\title{
The combination of reduced MCL-1 and standard chemotherapeutics is tolerable in mice
}

\author{
Kerstin Brinkmann ${ }^{1,2}$, Stephanie Grabow ${ }^{1,2}$, Craig D Hyland ${ }^{1}$, Charis E Teh ${ }^{1,2}$, Warren S Alexander ${ }^{1,2}$, Marco J Herold ${ }^{1,2}$ and \\ Andreas Strasser ${ }^{*, 1,2}$
}

A common therapeutic strategy to combat human cancer is the use of combinations of drugs, each targeting different cellular processes or vulnerabilities. Recent studies suggest that addition of an MCL-1 inhibitor to such anticancer drug treatments could be an attractive therapeutic strategy. Thus, it is of great interest to understand whether combinations of conventional anticancer drugs with an MCL-1 inhibitor will be tolerable and efficacious. In order to mimic the combination of MCL-1 inhibition with other cancer therapeutics, we treated $\mathrm{Mcl}^{-1^{+/}}$heterozygous mice, which have a 50\% reduction in MCL-1 protein in their cells, with a broad range of chemotherapeutic drugs. Careful monitoring of treated mice revealed that a wide range of chemotherapeutic drugs had no significant effect on the general well-being of $\mathrm{Mcl}^{+/-}$mice with no overt damage to a broad range of tissues, including the haematopoietic compartment, heart, liver and kidney. These results indicate that MCL-1 inhibition may represent a tolerable strategy in cancer therapy, even when combined with select cytotoxic drugs.

Cell Death and Differentiation (2017) 24, 2032-2043; doi:10.1038/cdd.2017.125; published online 11 August 2017

Inefficient activation of apoptosis is considered to be responsible (at least in part) for the resistance of tumour cells to a broad range of anticancer treatments. ${ }^{1-4}$ The mitochondrial apoptotic pathway is regulated by the pro-apoptotic multi$\mathrm{BH}$ (BCL-2 homology) domain proteins BAX, BAK and BOK, the pro-apoptotic BH3-only proteins BAD, BIK, BID, BIM, BMF, NOXA, HRK, PUMA and the anti-apoptotic BCL-2 proteins $\mathrm{BCL}-2, \mathrm{BCL}-\mathrm{XL}, \mathrm{BCL}-\mathrm{W}, \mathrm{A} 1, \mathrm{MCL}-1$ via protein-protein interactions. ${ }^{5,6}$ Depending on their relative expression levels in cancers, different anti-apoptotic BCL-2 proteins represent promising therapeutic targets.

MCL-1 is unique among the anti-apoptotic BCL-2 proteins as it is important for the survival of many cell types. Constitutive loss of MCL-1 causes embryonic lethality (E3.5). ${ }^{7}$ Tissue-specific ablation $\mathrm{Mcl}-1$ (both alleles) in adult mice demonstrated that MCL-1 is essential for the survival of haematopoietic stem/progenitor cells, ${ }^{8} \mathrm{~B}$ and $\mathrm{T}$ cells, ${ }^{9}$ plasma cells, ${ }^{10}$ neutrophils, ${ }^{11}$ basophils, ${ }^{12}$ mast cells, ${ }^{12}$ cardiomyocytes $^{13,14}$ and hepatocytes. ${ }^{15,16}$ The Mcl-1 gene locus is amplified in many (at least 10\%) human cancers, including acute myeloid leukaemia $(\mathrm{AML}),{ }^{17}$ mantle cell lymphoma $(\mathrm{MCL}){ }^{18}$ diffuse large B-cell lymphoma, nonHodgkin's lymphoma $(\mathrm{HL})^{19}$ and multiple myeloma $(\mathrm{MM}) .^{20}$ Genetic studies using mouse models revealed that inducible loss of MCL-1, in the case of C-MYC-driven lymphomas even loss of one $\mathrm{Mcl}-1$ allele, resulted in efficient killing of cancers. ${ }^{21-24}$ Conversely, overexpression of MCL-1 enhanced c-MYC- and v-ABL-driven lymphoma and plasmacytoma development, respectively. ${ }^{25-27}$ Hence, it was hypothesised that inhibitors of $\mathrm{MCL}-1$ (BH3 mimetics) may efficiently kill tumour cells. Excitingly, a potent and highly specific MCL-1 inhibitor, S63845, was recently developed and first evaluations demonstrated great potential against diverse tumours and tolerability in preclinical models of cancer. ${ }^{28}$

A common strategy for cancer therapy is the combinatorial use of several drugs targeting different cellular pathways and vulnerabilities. ${ }^{1,2}$ Thus, it is important to understand whether combined therapies including conventional anticancer drugs and MCL-1 inhibitors are tolerable and efficacious. Notably, our laboratory has recently shown that loss of one allele of Mcl-1 severely compromised haematopoietic recovery after myeloablative challenge. ${ }^{29}$ This suggested that a combination of MCL-1 inhibitors and DNA-damaging drugs may cause unacceptable toxicity. The MCL-1 inhibitor S63845 is unfortunately not yet available at an affordable cost for large scale in vivo testing. Therefore, in order to mimic the combination of drug-mediated loss of MCL-1 function with chemotherapeutics, we exposed $\mathrm{Mcl}-1^{+/-}$mice, which have a $\sim 50 \%$ reduction in $\mathrm{MCL}-1$ protein, to a broad range of drugs at clinically relevant doses. Upon treatment, the health of the ${\mathrm{Mcl}-1^{+/-}}^{-}$ mice was monitored with specific attention to changes in the haematopoietic compartment. The results of these studies provide important information for the safety of MCL-1 Inhibitors when used in clinical combination therapies for cancer.

\section{Results}

Reduction in MCL-1 causes a significant albeit minor reduction in certain blood cell subsets. MCL-1 is essential for the survival of a many cell types. ${ }^{8-16}$ Here we show that organism-wide constitutive loss of a single $\mathrm{Mcl}-1$ allele reduces MCL-1 protein levels by $30-50 \%$, depending on the

${ }^{1}$ Cancer and Haematology Division, The Walter and Eliza Hall Institute of Medical Research, Parkville, VIC, Australia and ${ }^{2}$ Department of Medical Biology, Molecular Genetics of Cancer Division, University of Melbourne, Melbourne, VIC, Australia

*Corresponding author: A Strasser, The Walter and Eliza Hall Institute of Medical Research, 1G Royal Parade, Parkville, VIC 3052 , Australia. Tel: +61 393452624 ; Fax: + 61-3-9347-0852; E-mail: strasser@wehi.edu.au

Received 18.3.17; revised 14.6.17; accepted 03.7.17; Edited by G Melino; published online 11.8.17 
cell type (Figure 1a and Supplementary Figure S1a). The levels of other anti-apoptotic (BCL-2 and BCL-XL) or proapoptotic (BIM) BCL-2 family members were comparable across several haematopoietic cell subsets between
$\mathrm{Mcl}^{-1^{+/}}$and wild-type mice (Figure 1a and Supplementary Figure S1a).

In $\mathrm{Mcl}-1^{+/-}$mice, the lymphoid and other haematopoietic cell types were reduced to a significant, albeit relatively a
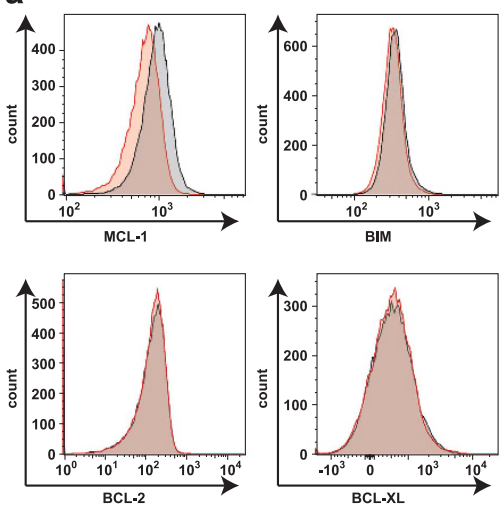

b

C

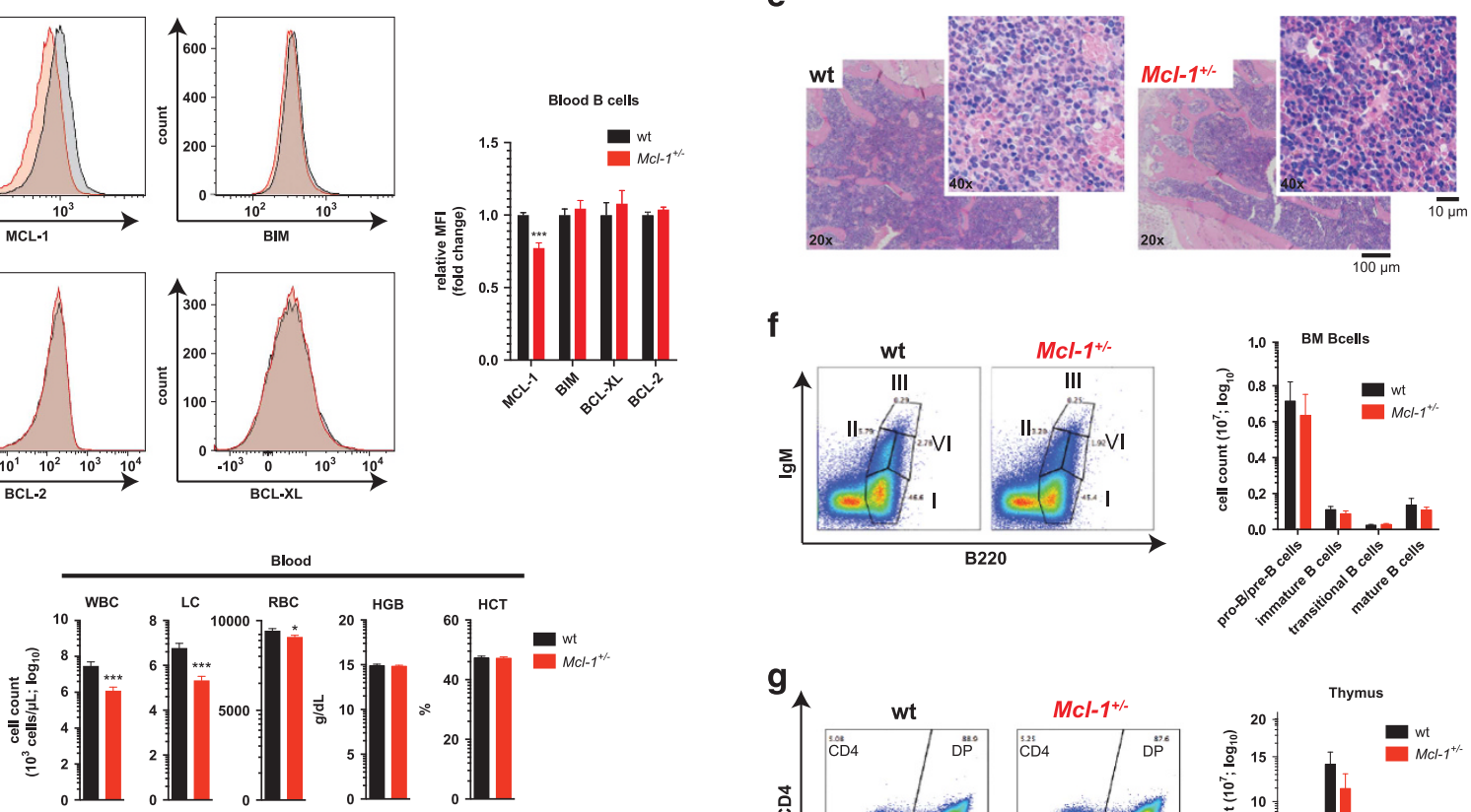

f


9


Figure 1 Reduction in MCL-1 levels causes a significant albeit minor loss of certain blood cell subsets. (a) Representative example of intracellular FACS staining for MCL-1, BIM, BCL-2 and BCL-XL in B220 $0^{+}$gated B cells from the blood of wild-type (wt) and $\mathrm{MCl}-1^{+/-}$mice (left panel). Data in the right panel represent relative mean fluorescence intensity (MFI) \pm S.E.M. in wild-type ( $n \geq 5)$ and $M c l-1^{+/-}$mice $(n \geq 5)$. ${ }^{* \star *} P<0.001$ (Student's $t$-test, two tailed, unpaired). (b) Total white blood cell (WBC), lymphocyte (LC), RBC numbers, haemoglobin content (HGB) and haematocrit (HCT) in peripheral blood of wild-type $(n=42)$ and $M c l-1^{+/}(n=54)$ mice. Data represent mean + S.E.M. ${ }^{*} P<0.05,{ }^{* \star} P<0.01,{ }^{* \star *} P<0.001$ (Student's $t$-test, two tailed, unpaired). (c) Representative examples of flow cytometric analysis of $T$ cells, $B$ cells (left panel) and myeloid cells (right panel) identified by surface staining for TCR $\beta /$ B220 and MAC-1/GR-1, respectively, in the peripheral blood of wild-type and Mcl- $1^{+/-}$mice. (d) Data are presented as mean \pm S.E.M. of total numbers of the indicated cell types in peripheral blood, spleen and bone marrow (BM) of wild-type $(n=7)$ and $M c l-1^{+/-}(n=7)$ mice. $P>0.5$ (n.s.) (Student's $t$-test, two tailed, unpaired, comparing wild-type with $\mathrm{Mcl}^{+1^{+-}}$mice). (e) Histological analysis of H\&E-stained sections of the BM (sternum) of wild-type and $\mathrm{Mcl}-1^{+/-}$mice. (f) Representative examples of flow cytometric analysis of the indicated B-cell populations identified by staining for IgM/B220. I= pro-B/pre-B, II = immature B; III = transitional B; IV = mature $B$ cells (left panel). Data are presented as mean \pm S.E.M. of the total numbers of the indicated cell subsets in the bone marrow (total cell count per one femur) of wild-type $(n=7)$ and ${\mathrm{Mcl}-1^{+/-}}^{+}(n=7)$ mice (right panel). $P>0.5$ (n.s.) (Student's $t$-test, two tailed, unpaired, comparing wild-type with Mcl- $1^{+/-}$mice). (g) Representative examples of flow cytometric analysis of thymic T-cell populations identified by staining for CD4/CD8 (left panel). Data are presented as mean \pm S.E.M. of total numbers of the indicated cell subsets in the thymi from wild-type $(n=7)$ and $\mathrm{Mcl}^{-1^{+-}}(n=7)$ mice (right panel). $P>0.5$ (n.s.) (Student's $t$-test, two tailed, unpaired, comparing wild-type with $\mathrm{Mcl}^{-1^{+/}-}$mice). DN = double negative; DP = double positive; SP single positive. (h) Representative examples of flow cytometric analysis of long-term haematopoietic stem cells (LT-HSC) identified by staining with lineage marker cocktail antibodies, and antibodies against c-KIT, SCA-1, CD48 and CD150. Lin- (lineage negative), LSK (Lin ${ }^{-} \mathrm{c}-\mathrm{KIT} \mathrm{T}^{+} \mathrm{SCA}-1^{+}$ (left panel)). Data are presented as mean \pm S.E.M. of the total numbers of the indicated cell subsets in the bone marrow (total cell count per one femur) of wild-type $(n=5)$ and $M c l-1^{+/-}(n=5)$ mice (right panel). $P>0.5$ (n.s.) (Student's $t$-test, two tailed, unpaired, comparing wild-type with $M c l-1^{+/-}$mice) 
minor, extent compared with wild-type mice (Figure 1 and Supplementary Figure S1). The numbers of all cell subsets analysed were reduced to a similar extent (Supplementary Figure $\mathrm{S} 1 \mathrm{~b}$ ), consistent with prior observations that MCL-1 is essential for the survival of several haematopoietic cell types. ${ }^{8-12}$ Although the $\mathrm{Mcl}-1^{+/-}$mice presented with a minor reduction in red blood cells (RBCs) compared with wild-type controls (Figure 1b), they were not anaemic as shown by their normal haemoglobin content (HGB) and haematocrit (HCT) (Figure 1b). This is likely due to compensatory processes resulting in a slight increase in median corpus volume and median haemoglobin content of their RBCs (Supplementary Figure S1c).

Further analysis of haematopoietic cells in blood, spleen and bone marrow confirmed a slight decrease in the numbers of several haematopoietic cell types, such as lymphoid (T and $B$ cells) and myeloid cells (MAC-1+ monocytes/macrophages, $\mathrm{MAC}-1^{+} \mathrm{GR}-1^{+}$granulocytes) (Figures $1 \mathrm{c}$ and $\mathrm{d}$ ). A small reduction in total cell numbers was observed for immature and mature $B$ and $T$ cells in the bone marrow (Figure 1f) and thymus (Figure 1g), respectively. Furthermore, a reduction in haematopoietic stem cells (LT-HSCs) was observed in mice with reduced $\mathrm{MCL}-1$ expression (Figure 1h). Analysis of $\mathrm{H} \& \mathrm{E}-$ stained sections of the bone marrow (sternum section) (Figure 1e) and spleen (Supplementary Figure S1e) confirmed a small reduction in overall cellularity in these tissues in $\mathrm{Mcl}-1^{+/-}$mice, but no severe cytopenia was ever observed.

Collectively, these results show that loss of one allele of Mcl-1 causes a significant, albeit minor, reduction in several haematopoietic cell subsets, even in the absence of stress, but does not lead to compensatory changes in the levels of other $\mathrm{BCL}-2$ protein family members.

Reduction in MCL-1 levels does not negatively impact on the general health of mice treated with standard chemotherapeutics. A common side effect of standard chemotherapy in clinical settings is bone marrow cytopenia with depletion of cycling immature progenitors, lymphocytes and other blood cells. We believe that the $30-50 \%$ reduction in MCL-1 protein levels, which is not compensated by readily detectable changes in the expression of other BCL-2 family members, in $\mathrm{Mcl}-1^{+/-}$mice is a reasonable mimic of drugmediated inhibition of MCL-1. Of note, the reduction in leukocytes in $\mathrm{Mcl}^{-1^{+/}-}$mice observed here (Figure 1) is similar to that detected in wild-type mice treated with the MCL-1 inhibitor S63845. ${ }^{28}$

To identify potential toxic side effects caused by the combination of reduction/inhibition of $\mathrm{MCL}-1$ protein and standard chemotherapy, $\mathrm{Mcl}-1^{+/-}$and, as a control, wildtype mice were treated with seven clinically relevant chemotherapeutic drugs. These included 5-FU (fluorouracil and adrucil), cytarabine (cytosine arabinoside and ara-C), hydroxyurea (hydroxycarbamide, hydrea, litalir and droxia), etoposide (etopophos and toposar), doxorubicin (adriamycin, doxil, caelyx and myocet), dexamethasone and paclitaxel (taxol, abraxane and onxol). These drugs were used at doses and schedules adjusted to conventional clinical protocols for the treatment of leukaemia and lymphoma patients (http://www. fda.gov/Regulatorylnformation/Guidances, Supplementary Figure S2).
Although high doses of $5-\mathrm{FU}(150 \mathrm{mg} / \mathrm{kg})$ caused the death of $\mathrm{Mcl}-1^{+/-}$but not wild-type mice (Figure $2 \mathrm{~b}$ and Delbridge et al. $^{29}$ ), clinically relevant (more moderate: $100 \mathrm{mg} / \mathrm{kg}$ ) doses

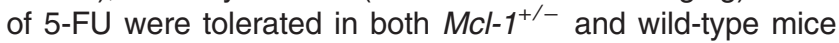
(Figures $2 b-e$ ). Similar results were obtained with moderate doses of cytarabine, hydroxyurea, etoposide, doxorubicin, dexamethasone and paclitaxel. We observed no obvious abnormalities in behaviour, breathing, food intake or weight loss, as general markers for normal function of the neuronal, cardiovascular and digestive systems, or anaemia (Figure 2e). These results show that the chemotherapeutic drugs tested did not cause overt pathology in mice with reduced MCL-1 levels.

Reduction in MCL-1 levels only moderately exacerbates the haematopoietic cytopenia caused by treatment with drugs that interfere with DNA synthesis. To test potential toxicity to the haematopoietic compartment exerted by anticancer drugs that interfere with DNA synthesis combined with reduced $\mathrm{MCL}-1$ expression, $\mathrm{Mcl}-1^{+/-}$and wild-type mice were treated with clinically relevant doses of 5-FU, cytarabine and hydroxyurea (Supplementary Figure S2). These drugs were shown to activate the mitochondrial apoptotic cell death pathway mainly by inducing DNA damage during DNA replication as a result of interfering with the supply of metabolites needed for DNA synthesis. 5-FU inhibits thymidylate synthase and thereby decreases the supply of thymidine. Hydroxyurea suppresses ribonucleotide reductase, thereby decreasing the production of all deoxyribonucleotides required for DNA synthesis. Cytarabine consists of a cytosine base linked to an arabinose sugar, which is rapidly converted into the anti-metabolite cytosine arabinose triphosphate. Owing to its similarity to deoxycytidine triphosphate cytosine arabinose triphosphate is incorporated into DNA during synthesis, thereby causing a stop in DNA replication (http://www.fda.gov).

Treatment of mice with moderate doses of 5-FU, cytarabine or hydroxyurea resulted in mild leukopenia (low WBC count) (Figure $3 a$ and Supplementary Figure S3a), anaemia (low RBC count) (Figure $3 \mathrm{~b}$ ) and thrombocytopenia (low platelet count) (Supplementary Figure S3b) in both ${\mathrm{Mcl}-1^{+/-}}^{-}$ and wild-type mice. This was slightly exacerbated in $\mathrm{Mcl-1^{+/- }}$ compared with wild-type mice (Figure 3).

As expected, all three drugs exerted readily detectable bone marrow toxicity ${ }^{30}$ with slightly more severe damage seen in $\mathrm{Mcl}-1^{+/-}$mice, as revealed by the examination of H\&E-stained sections of the sternum (Figure $3 \mathrm{c}$ ). Flow cytometric analysis identified a decrease in the B-cell, T-cell and monocyte/ macrophage populations in the bone marrow 7 days posttreatment (Figure 3d). Specifically, treatment with 5-FU, cytarabine and hydroxyurea resulted in the depletion of several B lymphoid subsets, including pro-B/pre-B (B200 $\left.\mathrm{slg}^{-}\right)$, immature, transitional and mature B cells $\left(B 200^{+} \mathrm{slg}^{+}\right)$ (Figure 3e). All of these B-cell populations were more severely depleted in $\mathrm{Mcl}-1^{+/-}$mice compared with wild-type controls. Remarkably, although $\mathrm{Mcl}_{-1} 1^{+/-}$mice were unable to repopulate their haematopoietic compartment after treatment with high doses of $5-\mathrm{FU},{ }^{29}$ LT-HSCs were efficiently mobilised to repopulate the haematopoietic compartment in both ${\mathrm{Mcl}-1^{+/-}}^{-}$ 
a

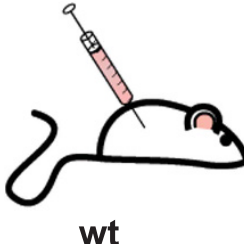

$\mathrm{Mcl}-1^{+/-}$

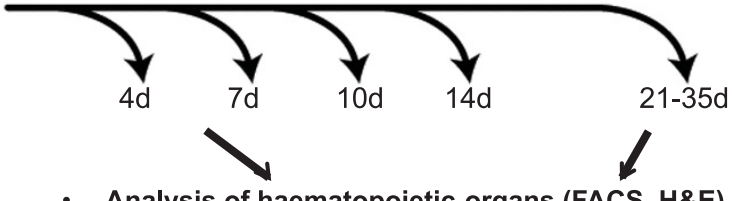

- Analysis of haematopoietic organs (FACS, H\&E)

- Analysis of organ function (monitoring of general health and behaviour, histologic examination)

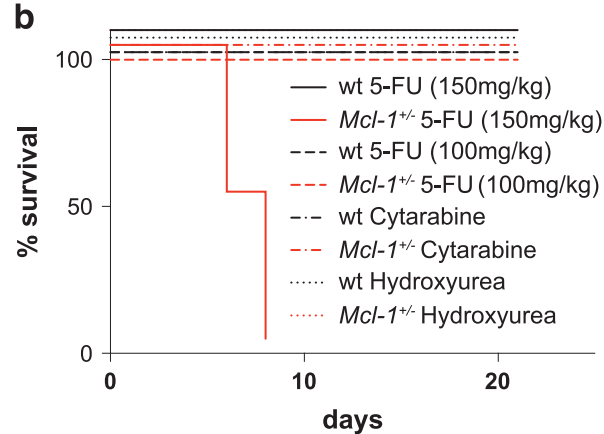

d

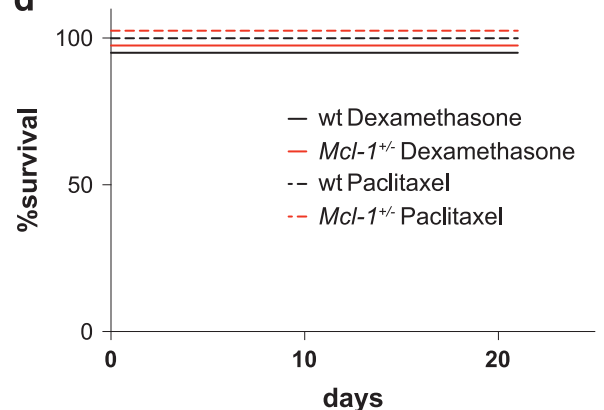

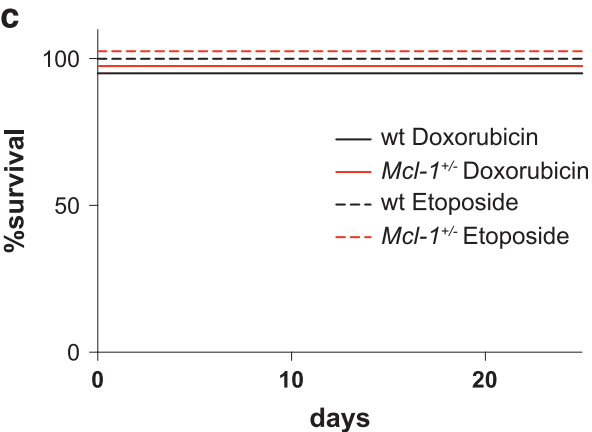

e

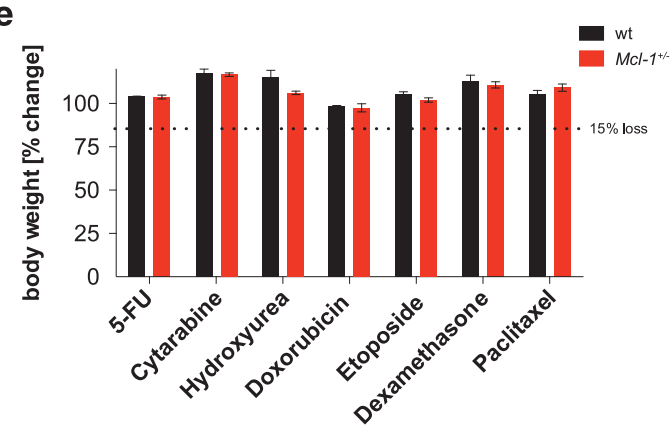

Figure 2 Reduction in MCL-1 levels does not negatively impact on the general health of mice treated with standard chemotherapy. (a) Study design: $M c l-1^{+/-}$and wild-type (wt) mice were treated with clinically relevant regimens of chemotherapeutic drugs, including 5-fluorouracil (5-FU), hydroxyurea, cytarabine, etoposide, doxorubicin, dexamethasone and paclitaxel. Upon treatment, the general health, including weight and signs of anaemia, were carefully monitored for a minimum of 21 days. Furthermore, the haematopoietic cell subset composition was analysed on days $0,4,7,10,14$ and 21-35 days post-treatment. Peripheral blood samples were analysed using FACS and ADVIA, and the absolute numbers of white blood cells, RBCs, lymphocytes and platelets were determined. Haemoglobin content and RBC quality (median corpuscular volume and haemoglobin content in RBC) were also assessed. At day 7 post-treatment, a group of mice from each treatment cohort was killed for a detailed analysis of their haematopoietic system and other tissues. (b-d) Kaplan-Meier survival curves of mice treated with the indicated chemotherapeutic drugs. (e) Body weight change $(\%)$ of wild-type $(n>3)$ and $\mathrm{MCl}-1^{+/-}$mice $(n>3)$ after treatment with the indicated drugs was determined at the indicated time points post-treatment

and wild-type mice in response to clinically relevant doses of 5-FU and cytarabine, (Supplementary Figure S3d).

Notably, only treatment with hydroxyurea resulted in the depletion of granulocytes in the bone marrow, and this was comparable between $\mathrm{Mcl}-1^{+/-}$and wild-type mice (Figure 3d). Treatment with 5-FU, cytarabine and hydroxyurea caused only a relatively mild depletion of T-cell populations in the thymus, including CD4-CD8- (double negative = DN) progenitors, CD4 $+\mathrm{CD} 8+$ (double positive $=\mathrm{DP}$ ) precursors as well as CD4 +CD8- and CD4-CD8+ mature T cells (Figure 3f).

In the spleen, only treatment with hydroxyurea resulted in a substantial loss of $\mathrm{B}$ and $\mathrm{T}$ lymphocytes and myeloid cells (monocytes/macrophages, granulocytes), and this was comparable between $\mathrm{Mcl}-1^{+/-}$and wild-type mice. $\mathrm{Mcl}-1^{+/-}$and wild-type mice treated with cytarabine had an abnormally enlarged spleen after 7 days, accompanied by an increase in both lymphoid as well as myeloid cells. Treatment with 5-FU caused a reduction in splenic monocytes/macrophages in both $\mathrm{Mcl}-1^{+/-}$and wild-type mice and also a minor reduction in splenic B cells (Supplementary Figure S3c). Importantly, numbers of all haematopoietic cell subsets examined normalised in all $\mathrm{Mcl}-1^{+/-}$and wild-type mice and no cytopenia was observed in H\&E-stained sections of the sternum (Supplementary Figure S3e) and spleen (Supplementary Figure S3f) at the end of treatment.

Collectively, these findings reveal that 5-FU, cytarabine

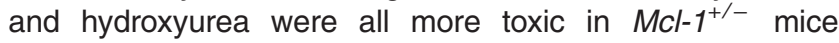
compared with wild-type controls, but both groups of animals could readily recover from the transient haematopoietic cytopenia. 



Reduction in MCL-1 levels only moderately exacerbates haematopoietic cytopenia caused by DNA double-strand break-inducing drugs. Having shown that mice with reduced MCL-1 expression could tolerate drugs that interfere with DNA synthesis, we next investigated whether this holds true for drugs that directly induce DNA damage, such as etoposide and doxorubicin. Etoposide, an inhibitor of topoisomerase II and doxorubicin, a DNA intercalating agent, both 
Figure 3 Reduction in MCL-1 levels only moderately exacerbates the haematopoietic cytopenia caused by treatment with drugs that interfere with DNA synthesis. Wild-type (wt) and $M \mathrm{Mcl}^{+1^{+/}-}$mice were treated with 5-fluorouracil $\left(1 \times 5\right.$-FU; $100 \mathrm{mg} / \mathrm{kg}$ body weight, i.v.; wild-type $\left.n=8 ; M c l-1^{+/-} n=8\right)$, cytarabine $(3 \times 80 \mathrm{mg} / \mathrm{kg}$ body weight, i.v.; wildtype $\left.n=10 ; \mathrm{Mcl}^{-1^{+/}-} n=9\right)$ or hydroxyurea $\left(3 \times 100 \mathrm{mg} / \mathrm{kg}\right.$ body weight, i.p.; wild-type $\left.n=12 ; \mathrm{Mcl}^{+1^{+-}} n=11\right)$ and monitored for a total of 21 days (5-FU, hydroxyurea) or 28 days (cytarabine). A subset of mice of each cohort was killed 7 days post-treatment for detailed flow cytometric and histological analysis. (a) Lymphocyte (LC) and (b) RBC numbers were determined in peripheral blood at the indicated time points post-treatment with 5-FU (left panel), cytarabine (middle panel) or hydroxyurea (right panel). Data represent mean \pm S.E.M. of the total numbers of the indicated cell types. ${ }^{*} P<0.05,{ }^{* \star} P<0.01,{ }^{* \star *} P<0.001$ (Student's $t$-test, two tailed, paired, compared with untreated). (c) Histological analysis of H\&E-stained sections of the bone marrow (sternum) of wild-type and $\mathrm{Mcl}-1^{+/}$mice 7 days post-treatment with 5-FU (upper panel), cytarabine (middle panel) or hydroxyurea (lower panel). Flow cytometric analysis of the indicated bone marrow (BM) cell populations (d) and indicated B-cell populations (e) (total cell count for one

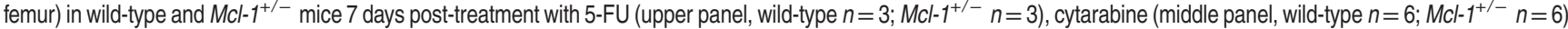
or hydroxyurea (lower panel, wild-type $\left.n=3 ; \mathrm{Mcl}^{-1^{+-}-} n=3\right)$, compared with untreated wild-type $(n=7)$ and $M c l-1^{+/-}$mice $(n=7)$. Data represent mean \pm S.E.M.. ${ }^{*} P<0.05$ (Student's $\mathrm{t}$-test, two tailed, unpaired, comparing wild-type with ${\mathrm{Mcl}-1^{+-}-}$mice). (f) Flow cytometric analysis of total thymic T lymphoid cells in wild-type and $\mathrm{Mcl}-\mathrm{1}^{+/-}$mice 7 days post-treatment with 5-FU (left panel, wild-type $n=3 ; \mathrm{Mcl}^{-1^{+-}} n=3$ ), cytarabine (middle panel, wild-type $n=6 ; \mathrm{Mcl}_{-1}{ }^{+/-} n=6$ ) or hydroxyurea (right panel, wild-type $n=3$;

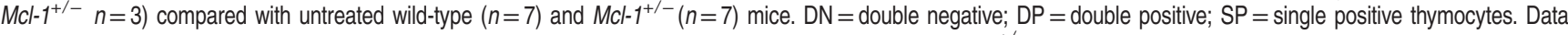
represent mean \pm S.E.M. $P>0.5$ (n.s.) (Student's $t$-test, two tailed, unpaired, comparing wild-type with $\mathrm{Mcl}^{-1^{+-}}$mice)

induce DNA double-strand breaks. ${ }^{31,32}$ This activates the intracellular DNA damage response machinery resulting in the induction of apoptosis. ${ }^{33}$

Strikingly, clinically relevant doses of these drugs were tolerated in all $\mathrm{Mcl}-1^{+/-}$and wild-type mice (Figures 2c and e). However, significant reductions in WBCs and RBCs were observed in both $\mathrm{Mcl}_{-1}{ }^{+/-}$and wild-type mice (Figures $4 \mathrm{a}$ and $\mathrm{b}$ and Supplementary Figures S4a and b). $\mathrm{Mcl}-1^{+/-}$and wild-type mice both presented with anaemia shortly after treatment (Figure 4b and Supplementary Figures S4c and d). Neither doxorubicin nor etoposide had a significant impact on platelet numbers in $\mathrm{Mcl}-1^{+/-}$or wild-type mice (Supplementary Figure S4b). $\mathrm{Mcl}-1^{+/-}$and wild-type mice both recovered from the drug-induced cytopenia and anaemia within 10-14 days, albeit with a marked delay seen in $\mathrm{Mcl}-1^{+/-}$mice.

Consistent with the loss of peripheral WBCs after treatment with etoposide or doxorubicin, severe bone marrow cytopenia was seen in both $\mathrm{Mcl}-1^{+/-}$and wild-type mice (Figures $4 \mathrm{c}-\mathrm{e}$ ). FACS analysis revealed that pro-B/pre-B, immature, transitional and mature $B$ cells as well as monocytes and macrophages but not granulocytes were significantly depleted in drug-treated animals (Figures $4 d$ and e). For all cell populations, the reduction was found to be more pronounced in $\mathrm{Mcl}-1^{+/-}$mice compared with wild-type controls. Treatment with doxorubicin also caused a substantial loss of thymic T cells, including DN progenitors, DP precursors and CD4+ as well as CD8+ mature single positive T cells in both $\mathrm{Mcl}-1^{+/-}$ and wild-type mice (Figure 4f, left panel). The cytotoxic effects of etoposide on thymic T lymphoid cells 7 days post-treatment, were less pronounced compared with those exerted by doxorubicin (Figure 4f, right panel). Notably, treatment with doxorubicin resulted in a marked loss of $B$, Tand myeloid cells (monocytes/macrophages and granulocytes) in the spleen, which was comparable between $\mathrm{Mcl}-1^{+/-}$and wild-type mice. $\mathrm{Mcl}-1^{+/-}$and wild-type mice treated with etoposide had a greatly enlarged spleen after 7 days, and this was accompanied by a pronounced increase in lymphoid cells (Supplementary Figure S4e). The $\mathrm{Mcl}-1^{+/-}$and wild-type mice both recovered from the doxorubicin or etoposide-induced cytopenia (Supplementary Figures S4f and $g$ ).

These results show that $\mathrm{Mcl}-1^{+/-}$mice can tolerate clinically relevant doses of doxorubicin and etoposide.

Reduction in MCL-1 levels does not drastically exacerbate haematopoietic cytopenia caused by non-DNAdamaging chemotherapeutic drugs. In order to gain a more comprehensive insight into possible combinatorial toxicities caused by reduction in MCL-1 levels with standard anticancer drugs, we also examined the impact of chemotherapeutics that do not induce DNA damage. The steroid dexamethasone and the tubulin toxin paclitaxel both activate the mitochondrial apoptotic pathway mainly through the induction of the pro-apoptotic BH3-only proteins BIM and, in the case of dexamethasone, also PUMA. ${ }^{34-36}$

Analysis of the blood revealed a significant decrease in WBCs (Supplementary Figure S5a), LCs (Figure 5a) and RBCs (Figure $5 \mathrm{~b}$ ) in $\mathrm{Mcl}-1^{+/-}$and wild-type animals treated with either of these drugs. The recovery of the WBC and RBC compartments was comparable between the $\mathrm{Mcl}_{-1} 1^{+/}$and wild-type mice. Treatment with dexamethasone and paclitaxel also induced bone marrow toxicity with prominent reductions in pro-B/pre-B, immature and mature $B$ cells as well as monocytes/macrophages but not granulocytes (Figures $5 \mathrm{c}-\mathrm{e}$ ). No significant differences between $\mathrm{Mcl}_{-1} \mathrm{1}^{+-}$and wild-type mice were observed. As expected, ${ }^{37}$ treatment with dexamethasone rapidly (within $48 \mathrm{~h}$ ) caused a depletion of thymic $\mathrm{T}$ cells, mainly affecting the CD4+CD8+ DP precursors (Supplementary Figure S5f). $M \mathrm{Cl}^{-1^{+/}-}$and wild-type mice both recovered from this toxic effect on T cells and no severe reduction was detectable 7 days after drug treatment (Figure 5f).

Treatment with paclitaxel also resulted in a depletion of splenic B and T cells 7 days post-treatment, and this was slightly more pronounced in mice with reduced MCL-1 (Supplementary Figure S5c). Histological analysis of the sternum and spleen revealed that all animals had fully recovered from their transient haematopoietic cytopenia by the end of the treatment (Supplementary Figures S5d and e).

These results show that dexamethasone and paclitaxel, anticancer drugs that do not induce DNA damage, cause severe transient depletion of WBCs and RBCs in $\mathrm{MCl}-1^{+/-}$and wild-type mice, but both sets of animals could readily recover.

Reduction in MCL-1 levels does not cause cardio-, nephro- or hepato-toxicity. Apart from the severe toxicity of chemotherapy on haematopoietic cells, resulting in transient anaemia and immunodeficiency, cardio-toxicity has been frequently reported for the treatment with 5-FU, doxorubicin, paclitaxel and dexamethasone (http://www.fda. gov/Regulatorylnformation/Guidances). Hydroxyurea has been shown to cause hepato- and nephro-toxicity. Notably, 


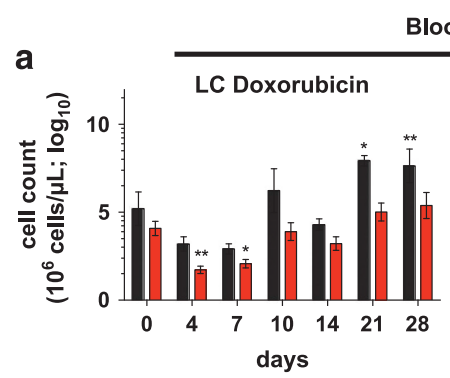

c
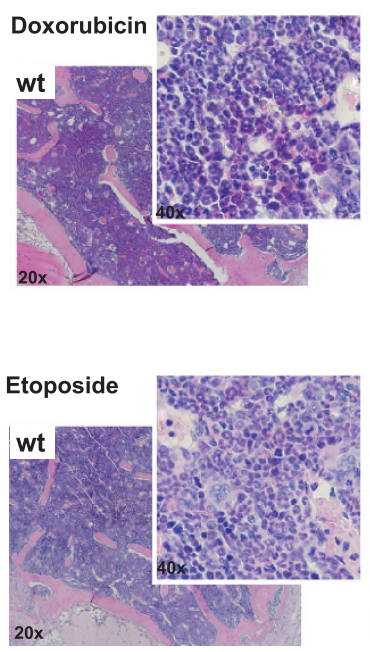

f



Blood



days
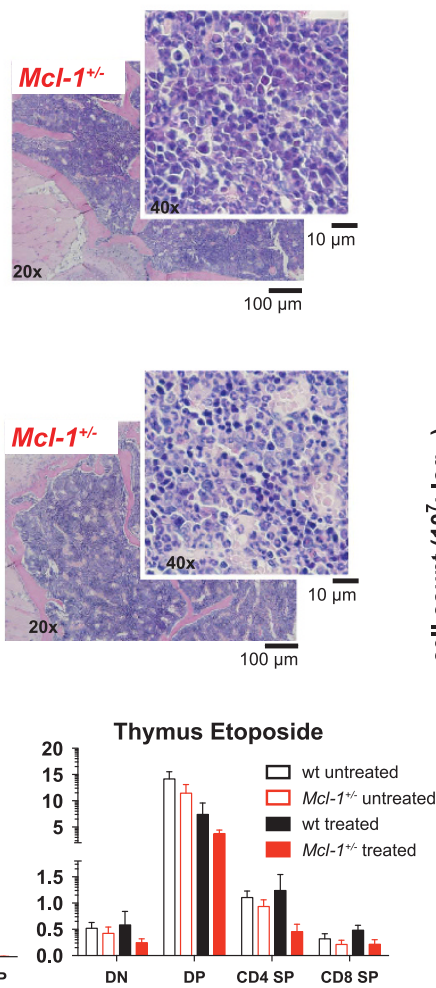

Thymus Etoposide

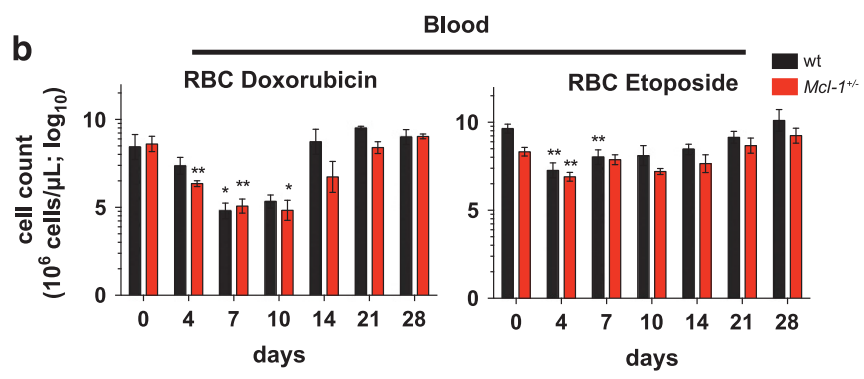

d

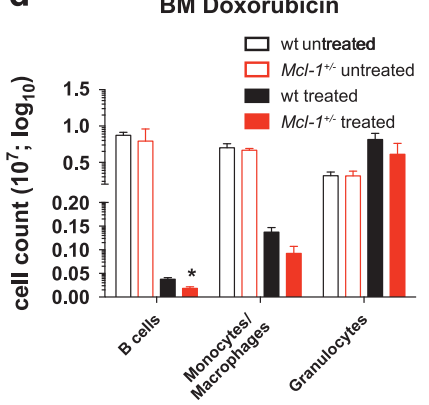

e
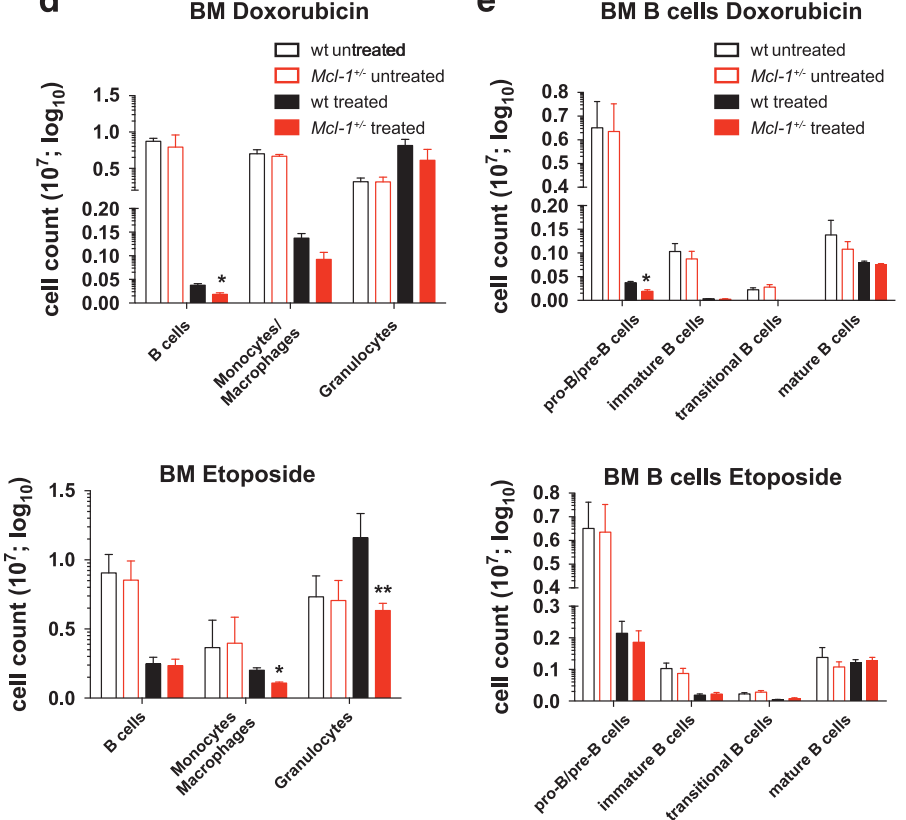

Figure 4 Reduction in MCL-1 levels only moderately exacerbates haematopoietic cytopenia caused by DNA double-strand break-inducing drugs. Wild-type (wt) and $M c l-1^{+/-}$mice were treated with doxorubicin $\left(2 \times 2 \mathrm{mg} / \mathrm{kg}\right.$ body weight, i.v.; wild-type $\left.n=9 ; M c l-1^{+/}-n=8\right)$ or etoposide $\left(1 \times 2 \mathrm{mg} / \mathrm{kg}\right.$ body weight, i.v.; wild-type $n=8$; $M \mathrm{Ml}^{-1} \mathrm{1}^{+/-}$ $n=8$ ) and monitored for a total of 28 days. A subset of each cohort was killed 7 days post-treatment for detailed flow cytometric and histological analysis. (a) Lymphocyte and (b) RBC numbers were determined in peripheral blood at the indicated time points post-treatment with doxorubicin (left panel) or etoposide (right panel). Data represent mean \pm S.E.M. ${ }^{*} P<0.05,{ }^{* *} P<0.01,{ }^{* * *} P<0.001$ (Student's $t$-test, two tailed, paired, compared with untreated mice). (c) Histological analysis of H\&E-stained sections of the bone

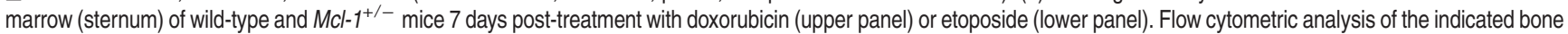
marrow (BM) cell populations (d) and the indicated B-cell populations (e) (total cell count for one femur) in wild-type and $\mathrm{Mcl}-1^{+/-}$mice 7 days post-treatment with doxorubicin

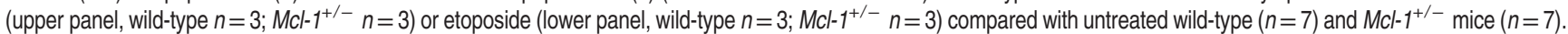
Data represent mean \pm S.E.M. ${ }^{*} P<0.05$ (Student's $t$-test, two tailed, unpaired, comparing wild-type with $M c l^{-1^{+-}}$mice). (f) Flow cytometric analysis of total thymic T lymphoid

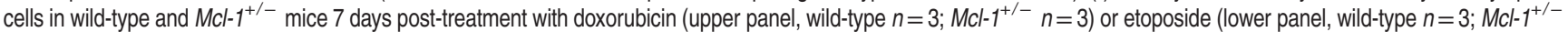


mean \pm S.E.M. $P>0.5$ (n.s.) (Student's t-test, two tailed, unpaired, comparing wild-type with ${\mathrm{Mcl}-1^{+/}-}$mice)

complete tissue-specific loss of MCL-1 was shown to cause severe, even fatal, damage to the heart ${ }^{13,14}$ and liver. ${ }^{15,16}$ Hence, reductions in MCL-1 expression may result in even more severe cardio-, hepato- and nephro-toxicity upon treatment with anticancer drugs.

To explore this, we treated ${\mathrm{MCl}-1^{+/}}^{+}$and wild-type mice with clinically relevant regimes of the chemotherapeutic drugs mentioned above, and tested whether ${\mathrm{Mcl}-1^{+/}}^{+}$mice were more severely affected. Careful monitoring of the treated mice, did not reveal a severe impact on their general well-being (including physical activity, breathing, food intake and excretion). Detailed histological examination did not reveal detectable damage to the heart, kidney and liver (Figures 6a-c and Supplementary Figures S6a-c) in drug-treated wild-type and $\mathrm{Mcl}-1^{+/-}$mice.

These results show that a reduction in MCL-1 expression does not cooperate with commonly used anticancer drugs to cause damage to the heart, liver or kidney. 
a

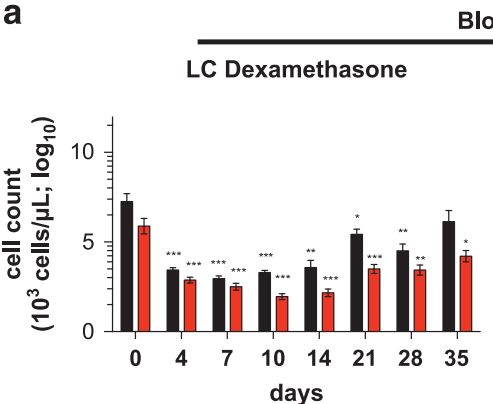

C
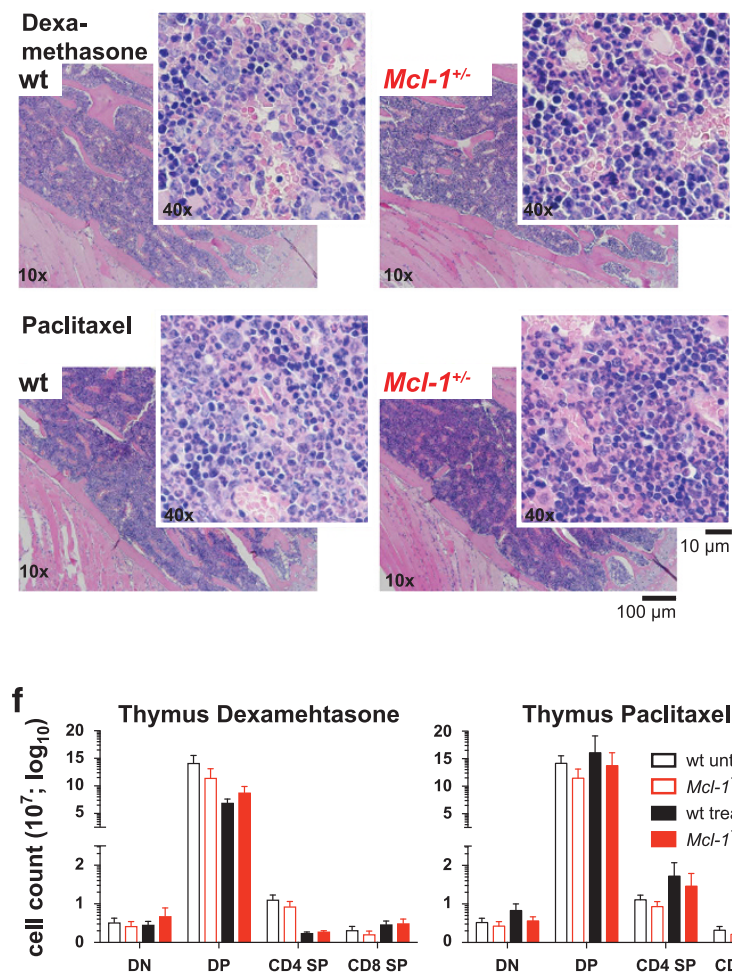

Blood



b

Blood
RBC Dexamethasone $\quad$ RBC Paclitaxel

wt

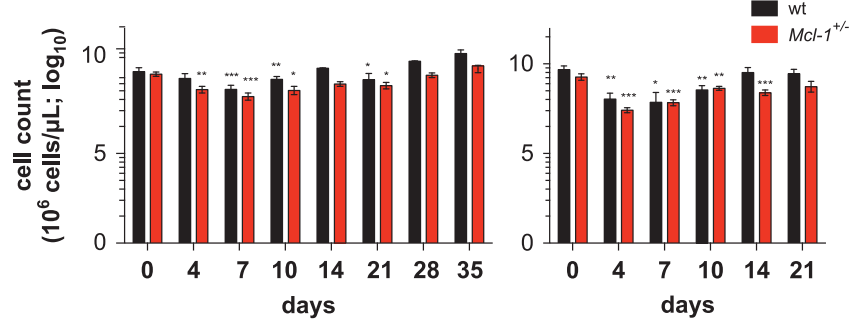

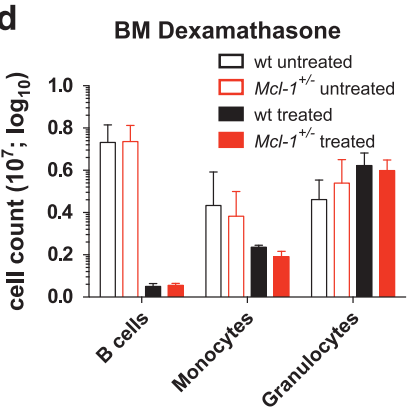

e BM B cells Dexamathasone
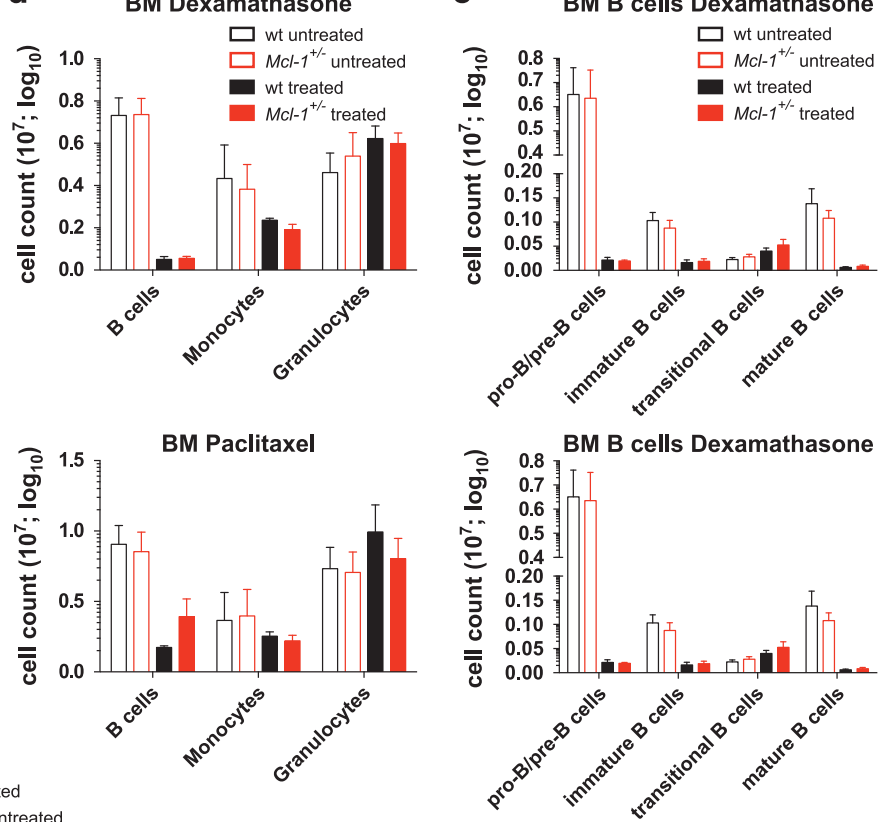

Figure 5 Reduction in MCL-1 levels does not drastically exacerbate haematopoietic cytopenia caused by non-DNA-damaging chemotherapeutic drugs. Wild-type (wt) and $\mathrm{Mcl}-1^{+/}$mice were treated with dexamethasone $\left(3 \times 10 \mathrm{mg} / \mathrm{kg}\right.$ body weight, i.v.; wild-type $\left.n=8 ; \mathrm{Mcl}^{-1^{+-}} n=13\right)$ or paclitaxel $(3 \times 3 \mathrm{mg} / \mathrm{kg}$ body weight, i.v.; wild-type $n=9$;


flow cytometric and histological analysis. (a) Lymphocyte and (b) RBC numbers were determined in peripheral blood at the indicated time points post-treatment with dexamethasone (left panel) or paclitaxel (right panel). Data represent mean \pm S.E.M. ${ }^{*} P<0.05,{ }^{* \star} P<0.01,{ }^{* * *} P<0.001$ (Student's $t$-test, two tailed, paired, compared with untreated). (c) Histological analysis of H\&E-stained sections of the bone marrow (sternum) of wild-type and $\mathrm{Mcl}-1^{+/-}$mice 7 days post-treatment with dexamethasone (upper panel) or paclitaxel (lower panel). Flow cytometric analysis of the indicated bone marrow (BM) cell populations (d) and the indicated B-cell populations (e) (total cell count for one femur) in wild-type and $\mathrm{MCl}^{+1^{+-}}$mice 7 days post-treatment with dexamethasone (upper panel; wild-type $n=3 ; \mathrm{MCl}^{+{ }^{+/}-} n=3$ ) or paclitaxel (lower panel); wild-type $n=3$; $\left.M \mathrm{MCl}-1^{+/-} n=3\right)$ compared with untreated wild-type $(n=7)$ and $M \mathrm{Ml}^{+1^{+/}}$mice $(n=7)$. Data represent mean \pm S.E.M. $P>0.5$ (n.s.) (Student's t-test, two tailed, unpaired, comparing wild-type with $\mathrm{MCl}_{-1} \mathrm{1}^{+/-}$mice). (f) Flow cytometric analysis of total thymic T cells in wild-type and ${\mathrm{Mcl}-1^{+/-}}$mice 7 days post-treatment with dexamethasone (left

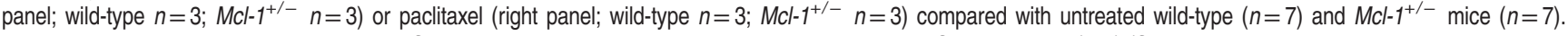
$\mathrm{DN}=$ double negative; $\mathrm{DP}=$ double positive; $\mathrm{SP}=$ single positive thymocytes. Data represent mean \pm S.E.M. $P>0.5$ (n.s.) (Student's t-test, two tailed, unpaired, comparing

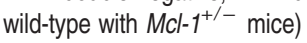

\section{Discussion}

MCL-1 represents a promising target for anticancer therapy. ${ }^{17-21,23}$ Excitingly, first preclinical studies with the recently described highly specific MCL-1 inhibitor, S63845, have shown that this drug is effective and tolerable in diverse murine cancer models. ${ }^{28}$ However, several haematological and solid cancers (e.g., a subset of human CML, breast cancer and melanoma cell lines tested), showed only moderate responses to $\mathbf{S} 63845$ as a single agent. Interestingly, many of these tumour-derived cell lines were potently killed by combinations of $\mathbf{S} 63845$ with other anticancer drugs. ${ }^{28}$ 
a

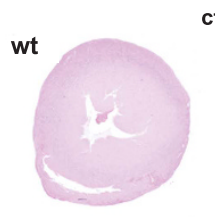

ctrl $\mathrm{Mcl}-1^{+/-}$

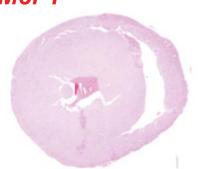

5-FU

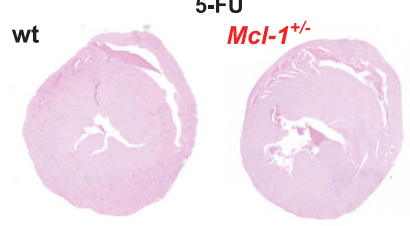

Cytarabine



$\mathrm{Mcl}-1^{+/}$
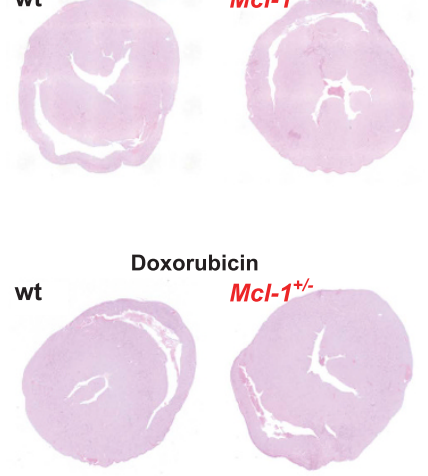

Doxorubicin

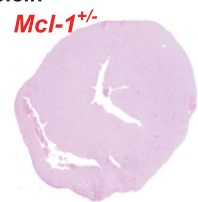

Dexamethasone



$\mathrm{Mcl}-1^{+/}$



C

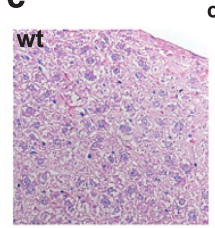

ctrl Mcl-1 $1^{+/}$

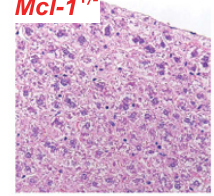

5-FU



b ctrl wt
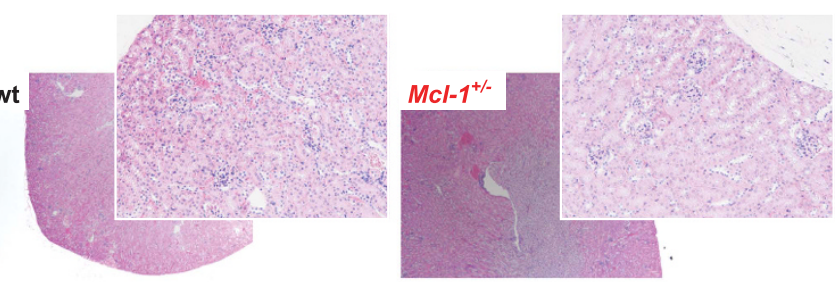

5-FU
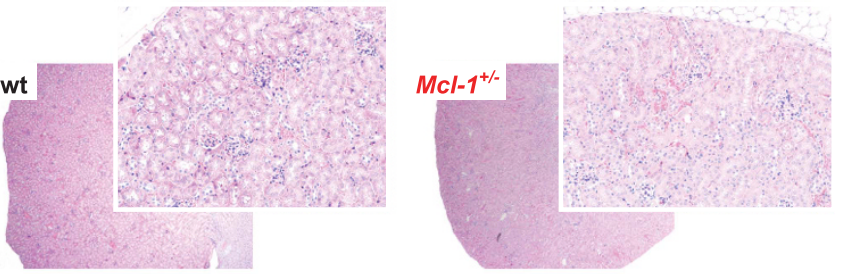

Doxorubicin

wt


Cytarabine

wt
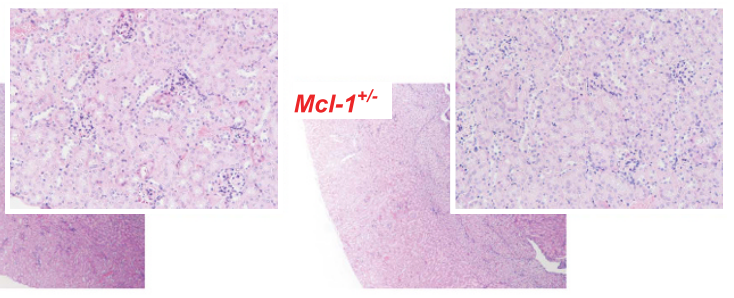

Dexamethasone

wt

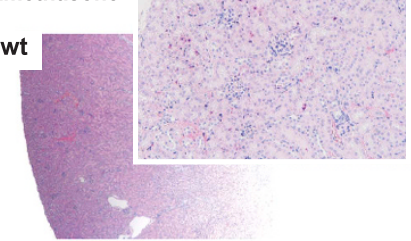

Cytarabine

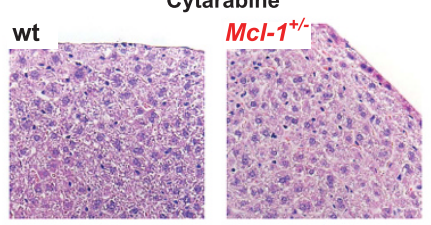

Doxorubicin

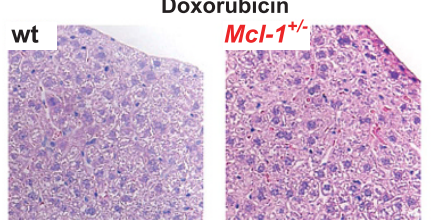

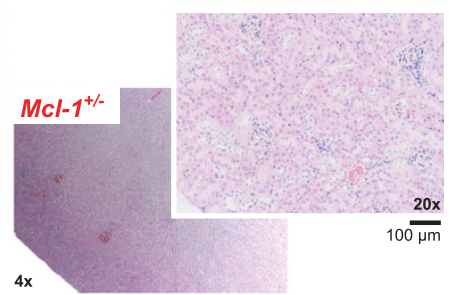

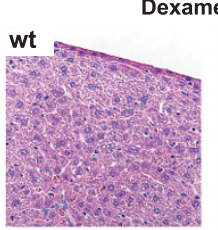

Dexamethasone

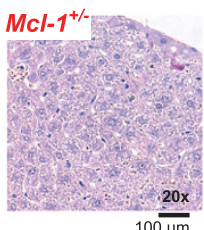

Figure 6 Reduction in MCL-1 levels does not cause cardio-, nephro- or hepato-toxicity. Histological analysis of H\&E-stained sections of the (a) heart, (b) kidney and (c) liver of wild-type (wt) and $\mathrm{Mcl}^{-1^{+/}}$mice that had been left untreated or treated with 5-FU (day 21 post-treatment), doxorubicin (day 28 post-treatment), cytarabine (day 21 posttreatment) or dexamethasone (day 35 post-treatment) as indicated 
However, no studies regarding the safety of the combinations of $\mathbf{S 6 3 8 4 5}$ or any other MCL-1 inhibitor with commonly used chemotherapeutics have been reported thus far. Our study in $\mathrm{Mcl}_{-1} 1^{+/-}$mice provides a comprehensive analysis of the in vivo toxicity of a broad range of chemotherapeutic drugs in mice with decreased MCL-1 expression. $\mathrm{Mcl}-1^{+/-}$ mice show a $30-50 \%$ reduction of $\mathrm{MCL}-1$ expression in their cells, mimicking drug-mediated MCL-1-inhibition. Importantly, no overt compensatory change in the expression of other BCL-2 protein family members was detected in various haematopoietic cell types. It was reported that complete loss of $\mathrm{MCL}-1$ in bone marrow resident macrophages leads to upregulation of BCL-2. ${ }^{11}$ However, we found only a minor increase in BCL-2 in peripheral blood monocytes/macrophages in $\mathrm{Mcl}^{-1 /-}$ mice but no increase in bone marrow resident macrophages. This indicates that only complete loss of MCL-1 selects for compensatory changes in the expression of other BCL-2 family members. Thus, we believe that our toxicity analyses in $\mathrm{Mcl}-1^{+/-}$mice are a fair representation of the combined treatment of chemotherapeutic drugs with the MCL-1 inhibitor S63845. Admittedly, preclinical and future clinical studies using MCL-1 inhibitors combined with standard chemotherapeutic drugs are required to establish efficient, non-toxic drug combinations.

Our findings show that anti-metabolic DNA-damaging drugs or drugs that activate the mitochondrial apoptotic pathway without engaging the DNA damage response machinery cause more severe haematopoietic cell depletion in $\mathrm{Mcl}-1^{+/-}$compared with wild-type mice. However, both cohorts of animals were able to fully recover.

As MCL-1 has an essential role in the survival of developing $B$ and $T$ cells, caution has to be taken when combining an MCL-1 inhibitor with drugs that impact on lymphocyte survival. ${ }^{38,39}$ Accordingly, for several of the anticancer drugs tested, a mild but significant exacerbation in the depletion of peripheral lymphocytes was seen in $\mathrm{Mcl}^{-1^{+/}}$compared with wild-type mice. Specifically, $\mathrm{Mcl}-1^{+/-}$mice exhibited a more profound depletion of several B-cell subsets in the bone marrow upon treatment with DNA-damaging drugs compared with wild-type mice. DNA damage results in the activation of ATM/ATR and ultimately in p53-mediated induction of the proapoptotic BH3-only proteins PUMA ${ }^{40}$ and NOXA. ${ }^{41}$ NOXA is a specific and highly potent inhibitor of MCL-1, whereas PUMA binds and inhibits all pro-survival BCL-2 family members, including MCL-1. ${ }^{42}$ Notably, NOXA-mediated inhibition of MCL-1 has been shown to be a critical determinant of the response of certain lymphoid cancers (e.g., CLL, HL, MM and $M C L$ ) to several chemotherapeutics, including DNA-damaging drugs. ${ }^{43-46}$ This may be attributed to NOXA-mediated increase of MCL-1 protein turnover. ${ }^{47}$ Accordingly, we found that cells with decreased MCL-1 levels were more susceptible to DNA damage-induced apoptosis compared with control cells.

Our study revealed that there was no increased vulnerability of lymphoid cells in $\mathrm{Mcl}-1^{+/-}$mice to killing induced by treatment with dexamethasone or paclitaxel. Similar to DNA damage-inducing anticancer drugs, dexamethasone and paclitaxel are both reported to induce the mitochondrial apoptotic pathway. However, in contrast to DNA damageinducing drugs, they act mainly through the induction of the pro-apoptotic proteins BIM and PUMA via a p53-independent pathway but not through p53-mediated activation of NOXA and PUMA. ${ }^{34-36}$ Although NOXA is only capable to bind and inhibit MCL-1 (and enhance its ubiquitin/proteasome-dependent degradation), BIM and PUMA can bind and inhibit all prosurvival BCL-2-family members, ${ }^{42}$ but they do not enhance MCL-1 degradation. Thus, dexamethasone and paclitaxel induced BIM (and PUMA) mediated apoptosis appears to be less dependent on specific antagonism of MCL-1 compared with cell death pathways that are driven to a substantial extent by NOXA. This may explain why reductions in $\mathrm{MCL}-1$ protein levels impact more substantially on cell killing induced by DNA-damaging drugs than dexamethasone or paclitaxel.

We observed no increased toxicity of the anticancer drugs tested in the heart, liver and kidneys in $\mathrm{Mcl}-1^{+/-}$mice compared with wild-type controls. This is surprising given that complete loss of MCL- 1 caused substantial, sometimes fatal, damage to these tissues. ${ }^{13-16}$ These seemingly discrepant findings may be reconciled by assuming that MCL- 1 must be completely removed to cause the death of cardiomyocytes and liver cells, even when animals are exposed to cytotoxic drugs. This is encouraging for the clinical testing of MCL-1 inhibitors, as treatment with such agents will only cause transient and partial inhibition of MCL-1 function.

Taken together, our studies suggest that combinations of MCL-1 inhibitors with diverse conventional anticancer drugs (including DNA damage-inducing drugs) may be tolerable. However, thorough preclinical drug dose escalation studies with particularly careful monitoring of the haematopoietic compartment are imperative before such treatments can be tested in cancer patients.

\section{Materials and Methods}

Chemotherapeutic drug treatments. Mice (10-12 weeks old, male and


injected with chemotherapeutic drugs as indicated. Working solutions of 5-FU, cytarabine, hydroxyurea, etoposide, doxorubicin, dexamethasone and paclitaxel (Sigma Aldrich, St. Louis, MO, USA) were prepared according to the manufacturer's instructions and a maximum volume of $200 \mu \mathrm{l}$ was injected into the tail vein (i.v.) or intraperitoneally (i.p.) as indicated.

Blood analysis. Mandible bleeds were taken at the indicated time points and haemogram analysis was performed using the ADVIA system (Siemens Healthcare Pty Erlangen, Germany). FACS analysis was performed as described below.

Flow cytometric analysis. Thymus, spleen and bone marrow cells were harvested and single-cell suspensions were prepared. Cells were counted using the CasyCell Counter (Schärfe System GmbH, Reutlingen, Germany). The numbers of haematopoietic cell subsets were determined by flow cytometric analysis using a FortessaX20 flow cytometer (BD Biosciences, San Jose, CA, USA). Cells were stained for the following haematopoietic cell subset-specific surface markers: B220 (RA3-6B2), IgM (5.1), CD4 (YTA3.2.1), CD8 (YTS169), GR-1 (RB6-8C5), MAC-1 (MI/70). Erythroid cells were removed from mandible bleeds using RBC lysis buffer before flow cytometric analysis. Single-cell suspensions were incubated with fluorochrome-conjugated monoclonal antibodies for $30 \mathrm{~min}$ on ice in buffered saline supplemented with $5 \%$ foetal bovine serum and 10\% 24G2 hybridoma supernatant (antibody against $\mathrm{F}(\gamma \mathrm{R}$ ) to block nonspecific antibody binding. After staining, cells were washed twice with buffered saline supplemented with $5 \%$ foetal bovine serum and analysed in the same buffer supplemented with propidium iodide (PI, $2 \mu \mathrm{g} / \mathrm{ml})$. Cell doublets and dead cells were identified and gated out using FSC-H/FSC-A and PI staining analysis, respectively. Intracellular staining was performed using the eBioscience (San Diego, CA, USA) FoxP3 Transcription Factor Staining Buffer Set according to the manufacturer's instructions using the following antibodies: antiMCL-1 (clone 19C4-15, WEHI, Pakville, VIC, Australia), ${ }^{49}$ anti-BCL-XL (clone E18, 
Abcam, Cambridge, UK), anti-BCL-2 (clone 10C4, eBioscience) and anti-BIM (clone $3 \mathrm{C} 5$, WEHI). Changes in median fluorescence intensity (MFI) were determined after normalising values (absolute MFI of the samples/background MFI of an unstained control). Data are presented as fold change to average MFI in cells from a C57BL/6 wild-type mouse. Pooled data from two independent analyses are shown. Haematopoietic stem cells (HSC) were analysed by cell surface staining with antibodies against HSC-specific markers: CD150-BV421 (clone TC15-12F12.2, Biolegend, San Diego, CA, USA), CD48-PECy7 (clone HM48-1, eBioscience), CD117-BV711 (clone 2B8, BD, Biosciences, San Jose, CA, USA ), SCA-1-A594 (eBioscience) and the lineage markers CD2-A700, CD4-A700, CD8-A700, GR-1-A700, F4/80-A700, CD19-A700, B220-A700, Ly6G-A700, TER119-A700, NK1.1-A700. The numbers of HSCs in untreated ${\mathrm{MCl}-1^{+/-}}^{+}$and wild-type mice were determined as described..$^{50}$ Chemotherapeutic drug treatment can result in the p53mediated downregulation of CD117. ${ }^{51}$ Therefore, HSCs in $\mathrm{MCl}_{-1+-}{ }^{+/}$and wild-type mice treated with 5-FU and cytarabine were identified by staining for CD48 and $\mathrm{CD} 150$ on lineage negative gated cells without employing a lineage ${ }^{-} \mathrm{C}-\mathrm{KIT}^{+} \mathrm{SCA}-1^{+}$ (LSK) gate as described. ${ }^{52}$

Statistical analysis. Blood and organ cell counts were plotted and analysed with GraphPad Prism (GraphPad Software, Inc., La Jolla, CA, USA) using the two-

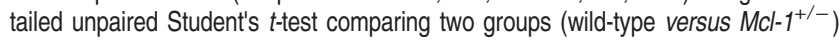
with each other. Blood cell counts from time course analyses were examined with Excel using the two-tailed paired Student's $t$-test, comparing values from untreated versus treated groups and plotted with GraphPad Prism. We found no evidence for deviation of the data points from a normal distribution, nor for differences in variance between groups of mice under analysis. Error bars represent \pm S.E.M. All data points were included in the final analysis, without exclusions. No randomisation methods were applied for sample treatment allocations.

\section{Conflict of Interest}

The authors collaborate with the pharmaceutical company Servier to develop MCL-1 inhibitors for cancer therapy. However, they have no financial interest in this drug development program.

Acknowledgements. We thank K Hughes, C D'Alessandro, K McKenzie, T Kitson, C Gatt and G Siciliano for expert animal care; B Helbert and K Mackwell for genotyping; J Corbin and J McManus for automated blood analysis; E Tsui, V Orlando, K Weston, Y Hoang, C Tsui, S Ter for help with histology, S Monard and his team for help with flow cytometry and $\mathrm{P}$ Bouillet for providing $\mathrm{Mcl}-1^{+/-}$mice and helping with histology assessment, D Grey for his advice for the intracellular FACS analysis of BCL-2 family members and for providing the relevant antibodies and staining solutions. This work was supported by grants and fellowships from the Deutsche Krebshilfe (Dr. Milded-Scheel-post-doctoral fellowship to KB) NHMRC fellowship (1020363), NHMRC program grant (1016701), LLS SCOR grant (7001-13) and CCV grant (1052309) (all to AS). Cancer Council Victoria Venture Grant and Victorian Cancer Agency (VCA TRP13041) (to MJH) NHMRC Fellowship (1058344), NHMRC Program Grant (1113577), NHMRC Independent Research Institutes Infrastructure Support Scheme Grant (361646), the Australian Cancer Research Fund and Victorian State Government Operational Infrastructure Support (all to WSA).

\section{Author contributions}

$\mathrm{KB}, \mathrm{SG}, \mathrm{MJH}$ and $\mathrm{AS}$ designed and conceived the study and experiments and prepared the manuscript. KB conducted and analysed the experiments. $\mathrm{CDH}$ and WSA provided advice for the analysis of the LT-HSC compartment and helped with the experiments and data analysis. CET performed the intracellular FACS analysis of BCL-2 family members.

1. Hanahan D, Weinberg RA. The hallmarks of cancer. Cell 2000; 100: 57-70.

2. Hanahan D, Weinberg RA. Hallmarks of cancer: the next generation. Cell 2011; 144: 646-674.

3. Letai AG. Diagnosing and exploiting cancer's addiction to blocks in apoptosis. Nat Rev Cancer 2008; 8: 121-132.

4. Cragg MS, Harris C, Strasser A, Scott CL. Unleashing the power of inhibitors of oncogenic kinases through BH3 mimetics. Nat Rev Cancer 2009; 9: 321-326.

5. Czabotar PE, Lessene G, Strasser A, Adams JM. Control of apoptosis by the BCL-2 protein family: implications for physiology and therapy. Nat Rev Mol Cell Biol 2014; 15: 49-63.
6. Chipuk JE, Moldoveanu T, Llambi F, Parsons MJ, Green DR. The BCL-2 family reunion. Mol Cell 2010; 37: 299-310.

7. Rinkenberger JL, Horning S, Klocke B, Roth K, Korsmeyer SJ. Mcl-1 deficiency results in peri-implantation embryonic lethality. Genes Dev 2000; 14: 23-27.

8. Opferman JT, Iwasaki H, Ong CC, Suh H, Mizuno S, Akashi K et al. Obligate role of anti-apoptotic MCL-1 in the survival of hematopoietic stem cells. Science 2005; 307: 1101-1104.

9. Opferman JT, Letai A, Beard C, Sorcinelli MD, Ong CC, Korsmeyer SJ. Development and maintenance of B and T lymphocytes requires antiapoptotic MCL-1. Nature 2003; 426: 671-676.

10. Peperzak V, Vikstrom I, Walker J, Glaser SP, LePage M, Coquery CM et al. Mcl-1 is essential for the survival of plasma cells. Nat Immunol 2013; 14: 290-297.

11. Dzhagalov I St, John A, He YW. The antiapoptotic protein Mcl- 1 is essential for the survival of neutrophils but not macrophages. Blood 2007; 109: 1620-1626.

12. Lilla JN, Chen CC, Mukai K, BenBarak MJ, Franco CB, Kalesnikoff J et al. Reduced mast cell and basophil numbers and function in Cpa3-Cre; Mcl-1fl/fl mice. Blood 2011; 118: 6930-6938.

13. Thomas RL, Gustafsson AB. MCL1 is critical for mitochondrial function and autophagy in the heart. Autophagy 2013; 9: 1902-1903.

14. Wang X, Bathina M, Lynch J, Koss B, Calabrese C, Frase $S$ et al. Deletion of MCL-1 causes lethal cardiac failure and mitochondrial dysfunction. Genes Dev 2013; 27: 1351-1364.

15. Hikita H, Takehara T, Shimizu S, Kodama T, Li W, Miyagi T et al. Mcl-1 and Bcl-xL cooperatively maintain integrity of hepatocytes in developing and adult murine liver. Hepatology 2009; 50: 1217-1226.

16. Vick B, Weber A, Urbanik T, Maass T, Teufel A, Krammer PH et al. Knockout of myeloid cell leukemia-1 induces liver damage and increases apoptosis susceptibility of murine hepatocytes. Hepatology 2009; 49: 627-636.

17. Okita H, Umezawa A, Fukuma M, Ando T, Urano F, Sano M et al. Acute myeloid leukemia possessing jumping translocation is related to highly elevated levels of EAT/mcl-1, a Bcl-2 related gene with anti-apoptotic functions. Leuk Res 2000; 24: 73-77.

18. Khoury JD, Medeiros LJ, Rassidakis GZ, McDonnell TJ, Abruzzo LV, Lai R. Expression of Mcl-1 in mantle cell lymphoma is associated with high-grade morphology, a high proliferative state, and p53 overexpression. J Pathol 2003; 199: 90-97.

19. Kuramoto K, Sakai A, Shigemasa K, Takimoto $Y$, Asaoku H, Tsujimoto T et al. High expression of MCL1 gene related to vascular endothelial growth factor is associated with poor outcome in non-Hodgkin's lymphoma. Br J Haematol 2002; 116: 158-161.

20. Zhang B, Gojo I, Fenton RG. Myeloid cell factor-1 is a critical survival factor for multiple myeloma. Blood 2002; 99: 1885-1893.

21. Glaser SP, Lee EF, Trounson E, Bouillet P, Wei A, Fairlie WD et al. Anti-apoptotic Mcl-1 is essential for the development and sustained growth of acute myeloid leukemia. Genes Dev 2012; 26: 120-125.

22. Grabow S, Delbridge AR, Valente LJ, Strasser A. MCL-1 but not BCL-XL is critical for the development and sustained expansion of thymic lymphoma in p53-deficient mice. Blood 2014; 124: 3939-3946.

23. Kelly GL, Grabow S, Glaser SP, Fitzsimmons L, Aubrey BJ, Okamoto T et al. Targeting of MCL-1 kills MYC-driven mouse and human lymphomas even when they bear mutations in p53. Genes Dev 2014; 28: 58-70.

24. Grabow S, Delbridge AR, Aubrey BJ, Vandenberg CJ, Strasser A. Loss of a single Mcl-1 allele inhibits MYC-driven lymphomagenesis by sensitizing pro-B cells to apoptosis. Cell Rep 2016; 14: 2337-2347.

25. Zhou P, Levy NB, Xie H, Qian L, Lee CY, Gascoyne RD et al. MCL1 transgenic mice exhibit a high incidence of B-cell lymphoma manifested as a spectrum of histologic subtypes. Blood 2001; 97: 3902-3909.

26. Vandenberg CJ, Cory S. ABT-199, a new Bcl-2-specific BH3 mimetic, has in vivo efficacy against aggressive Myc-driven mouse lymphomas without provoking thrombocytopenia. Blood 2013; 121: 2285-2288.

27. Vandenberg CJ, Waring $P$, Strasser A, Cory S. Plasmacytomagenesis in Emu-v-abl transgenic mice is accelerated when apoptosis is restrained. Blood 2014; 124: 1099-1109.

28. Kotschy A, Szlavik Z, Murray J, Davidson J, Maragno AL, Le Toumelin-Braizat G et al. The MCL1 inhibitor S63845 is tolerable and effective in diverse cancer models. Nature 2016; 538: 477-482.

29. Delbridge AR, Opferman JT, Grabow S, Strasser A. Antagonism between MCL-1 and PUMA governs stem/progenitor cell survival during hematopoietic recovery from stress. Blood 2015; 125: 3273-3280.

30. Chabner BA, Roberts TG Jr. Timeline: chemotherapy and the war on cancer. Nat Rev Cancer 2005; 5: 65-72.

31. Pommier $\mathrm{Y}$, Leo $\mathrm{E}$, Zhang $\mathrm{H}$, Marchand $\mathrm{C}$. DNA topoisomerases and their poisoning by anticancer and antibacterial drugs. Chem Biol 2010; 17: 421-433.

32. Tacar O, Sriamornsak P, Dass CR. Doxorubicin: an update on anticancer molecular action, toxicity and novel drug delivery systems. J Pharm Pharmacol 2013; 65: 157-170.

33. Brinkmann K, Schell M, Hoppe T, Kashkar H. Regulation of the DNA damage response by ubiquitin conjugation. Front Genet 2015; 6: 98.

34. Bouillet P, Metcalf D, Huang DC, Tarlinton DM, Kay TW, Kontgen F et al. Proapoptotic Bcl-2 relative Bim required for certain apoptotic responses, leukocyte homeostasis, and to preclude autoimmunity. Science 1999; 286: 1735-1738. 
35. Happo L, Strasser A, Cory S. BH3-only proteins in apoptosis at a glance. J Cell Sci2012; 125 (Pt 5): 1081-1087.

36. Puthalakath H, O'Reilly LA, Gunn P, Lee L, Kelly PN, Huntington ND et al. ER stress triggers apoptosis by activating BH3-only protein Bim. Cell 2007; 129: 1337-1349.

37. Herold MJ, McPherson KG, Reichardt HM. Glucocorticoids in T cell apoptosis and function. Cell Mol Life Sci 2006; 63: 60-72.

38. Dzhagalov I, Dunkle A, He YW. The anti-apoptotic Bcl-2 family member Mcl-1 promotes T lymphocyte survival at multiple stages. J Immunol 2008; 181: 521-528.

39. Vikstrom IB, Slomp A, Carrington EM, Moesbergen LM, Chang C, Kelly GL et al. MCL-1 is required throughout $\mathrm{B}$-cell development and its loss sensitizes specific B-cell subsets to inhibition of BCL-2 or BCL-XL. Cell Death Dis 2016; 7: e2345.

40. Nakano K, Vousden KH. PUMA, a novel proapoptotic gene, is induced by p53. Mol Cell 2001; 7: 683-694.

41. Oda E, Ohki R, Murasawa H, Nemoto J, Shibue T, Yamashita T et al. Noxa, a BH3-only member of the Bcl-2 family and candidate mediator of p53-induced apoptosis. Science 2000; 288: 1053-1058.

42. Adams JM, Cory S. The Bcl-2 apoptotic switch in cancer development and therapy. Oncogene 2007; 26: 1324-1337.

43. Brinkmann K, Kashkar H. Targeting the mitochondrial apoptotic pathway: a preferred approach in hematologic malignancies? Cell Death Dis 2014; 5: e1098.

44. Brinkmann K, Zigrino P, Witt A, Schell M, Ackermann L, Broxtermann P et al. Ubiquitin C-terminal hydrolase-L1 potentiates cancer chemosensitivity by stabilizing NOXA. Cell Rep 2013; 3: 881-891.
45. Gomez-Bougie P, Wuilleme-Toumi S, Menoret E, Trichet V, Robillard N, Philippe M et al. Noxa up-regulation and Mcl-1 cleavage are associated to apoptosis induction by bortezomib in multiple myeloma. Cancer Res 2007; 67: 5418-5424.

46. Perez-Galan P, Roue G, Villamor N, Montserrat E, Campo E, Colomer D. The proteasome inhibitor bortezomib induces apoptosis in mantle-cell lymphoma through generation of ROS and Noxa activation independent of p53 status. Blood 2006; 107: 257-264.

47. Gomez-Bougie P, Menoret E, Juin P, Dousset C, Pellat-Deceunynck C, Amiot M. Noxa controls Mule-dependent Mcl-1 ubiquitination through the regulation of the Mcl-1/USPgX interaction. Biochem Biophys Res Commun 2011; 413: 460-464.

48. Vikstrom I, Carotta S, Luthje K, Peperzak V, Jost PJ, Glaser S et al. Mcl-1 is essential for germinal center formation and B cell memory. Science 2010; 330: 1095-1099.

49. Okamoto T, Coultas L, Metcalf D, van Delft MF, Glaser SP, Takiguchi M et al. Enhanced stability of Mcl1, a prosurvival Bcl2 relative, blunts stress-induced apoptosis, causes male sterility, and promotes tumorigenesis. Proc Natl Acad Sci USA 2014; 111: 261-266.

50. Pronk CJ, Rossi DJ, Mansson R, Attema JL, Norddahl GL, Chan CK et al. Elucidation of the phenotypic, functional, and molecular topography of a myeloerythroid progenitor cell hierarchy. Cell Stem Cell 2007; 1: 428-442.

51. Abbas HA, Pant V, Lozano $G$. The ups and downs of $p 53$ regulation in hematopoietic stem cells. Cell Cycle 2011; 10: 3257-3262.

52. Kiel MJ, Yilmaz OH, Iwashita T, Yilmaz OH, Terhorst C, Morrison SJ. SLAM family receptors distinguish hematopoietic stem and progenitor cells and reveal endothelial niches for stem cells. Cell 2005; 121: 1109-1121.

Supplementary Information accompanies this paper on Cell Death and Differentiation website (http://www.nature.com/cdd) 